\author{
WORLD PRODUCT AND INCOME \\ A Review Article \\ Henri Theil* \\ University of Western Australia \\ and \\ University of Florida \\ Discussion Paper 82.19
}

September 1982

NMisha Strassberg Visiting Research Professor, Department of Economics, The University of Western Australia, July 1982, and McKethan-Matherly Professor of Econometrics and Decision Sciences, Graduate School of Business, University of Florida, Gainesville. 
WORLD PRODUCT AND INCOME

\section{A Review Article}

by

Henri Theil

University of Florida

\section{Introduction}

World Product and Income, International Comparisons of Real Gross Product by Irving B. Kravis, Alan Heston and Robert Summers appeared in the Spring 1982. This book is the third of a series, the two earlier volumes being Kravis et al. (1975, 1978a), published for the World Bank by the Johns Hopkins University Press. This series is the result of a large-scale research effort aimed at providing comparable price and volume indexes of gross domestic product and its components for a number of countries at different levels of affluence. Kravis et a1. (1975) considered ten countries, which were extended to sixteen in Kravis et a1. (1978a). I Thirty-four countries appear in the 1982 volume: the U. S., the nine countries of the European Economic Community (Belgium, Denmark, France, Germany, Ireland, Italy, Luxembourg, the Netherlands and the U. K.), six other European countries (Austria, Hungary, Poland, Romania, Spain and Yugoslavia), three African countries (Kenya, Malawi and Zambia), five in Latin America and the Caribbean (Brazil, Colombia, Jamaica, Mexico and Uruguay) and ten in Asia (India, Iran, Japan, Korea, Malaysia, Pakistan, the Philippines, Sri Lanka, Syria and Thailand). I should add that Kravis et al. (1978b) pro-

\footnotetext{
"I want to thank Tejaswi Raparla and Kathryn A. Yellé of the University of Florida for their research assistance; their work was in part supported by Grant SES-8023555 from the National Science Foundation. Also, I want to thank Kenneth $W$. Clements of the University of Western Australia for his comments on an earlier draft of this article.

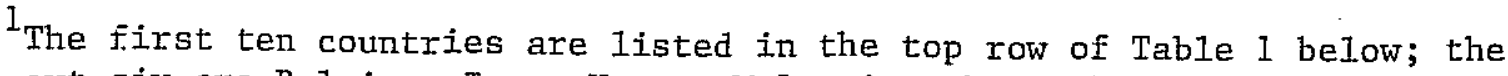
next six are Belgium, Iran, Korea, Malaysia, the Netherlands and the Philippines.
} 
vides rough estimates of the gross domestic product, but not its components, for more than 100 countries. More recently, Stumers et a1. (1980) provided such estimates for 1950 and each of the years from 1960 to 1977.

The work summarized above is the result of a joint effort of the University of Pennsylvania, the Statistical Office of the United Nations, and the World Bank. This collaboration has come to a close. Thus, the appearance of World Product and Income marks the end of a major research effort by its three authors, one of whom has been active in this area for some thirty years (Gilbert and Kravis, 1954). To a large degree, this work is in the tradition of that of Colin Clark (1940), Simon Kuznets (1956-67) and Wassily Leontief (1951, 1971). A review article is clearly appropriate.

\section{The Data and Their Construction}

The simplest way of comparing expenditures in different countries is by converting them into the same unit using the exchange rate of their currencies, but it has been known for a long time that this procedure is unsatisfactory. Kravis et al. are micro-oriented. They divided each country's gross domestic product into more than 150 "detailed categories.". One of these is fresh vegetables, which consists of 20 individual items as shown in Table $1 .^{2}$ Let $P_{i c}$ be the price of item $i$ in country $c$, expressed in that country's currency. The country-product-dumm (CPD) method describes the natural log of $P_{i c}$ as the sum of an item effect $A_{i}$ and a country effect $B_{c}$. If there are no missing price data and if this relation is estimated by least squares, the estimate of ${ }^{B}{ }_{c}$ is the mean over all items of $\log P_{i c}$ and, hence, the antilog of this estimate

This table is from Kravis et al. (1975, p. 59). I should mention here that some of the methodological issues have been treated more extensively in the earlier volumes. This is a bit hard for the user of the 1982 volume, but it is understandable that the authors wanted to avoid excessive repetition. 
Table 1

PRICES PER KILOGRAM OF FRESH VEGETABLES IN :10 COUNTRIES IN: 1970

\begin{tabular}{|c|c|c|c|c|c|c|c|c|c|c|c|}
\hline & $\begin{array}{l}\text { Tombia } \\
\text { Peso) }\end{array}$ & $\begin{array}{l}\text { France } \\
\text { (Franc) }\end{array}$ & $\begin{array}{l}\text { Germany } \\
\text { (D. Mark) }\end{array}$ & $\begin{array}{l}\text { Hungary } \\
\text { (Florint) }\end{array}$ & $\begin{array}{l}\text { India } \\
\text { (Rupee) }\end{array}$ & $\begin{array}{l}\text { Italy } \\
\text { (Lira) }\end{array}$ & $\begin{array}{l}\text { Japan } \\
\text { (Yen) }\end{array}$ & $\begin{array}{c}\text { Kenya } \\
\text { (Shilling) }\end{array}$ & $\begin{array}{l}\text { U.K. } \\
\text { (Pound) }\end{array}$ & $\begin{array}{c}\text { U.S. } \\
\text { (Dollar) }\end{array}$ & $\begin{array}{c}\text { Coefficient } \\
A_{j}\end{array}$ \\
\hline 7. Artichokes & - & 2.75 & 3.26 & $-\ldots$ & - & 646 & - & - & - & 2.22 & .56 \\
\hline 2. Beets & 3.90 & - & - & - & - & - & - & - & .07 & .42 & -.89 \\
\hline 3. Brussels sprouts & - & 2.35 & 1.69 & - & - & 485 & - & - & - & 1.89 & -.23 \\
\hline 4. Cabbage & 1.41 & .98 & .55 & 2.9 & .97 & 157 & 75.4 & .47 & .08 & .32 & -1.02 \\
\hline 5. Cauliflower & 5.33 & 1.90 & 1.13 & - & 1.27 & 195 & 156.6 & 2.58 & .17 & .63 & -.18 \\
\hline 6. Carrots & 2.70 & .93 & .86 & 3.2 & .75 & 172 & 175.1 & 2.58 & .07 & .39 & -.67 \\
\hline 7: Celery, pascal & 4.49 & - & - & - & - & - & - & - & - & .44 & -.59 \\
\hline 8. Cucumbers & - & - & - & 4.7 & .87 & - & 173.3 & - & - & .61 & -.39 \\
\hline 9. Eggplant & - & - & - & - & .72 & - & - & - & - & .59 & -.63 \\
\hline 10. Escarole & - & 1.82 & .98 & - & $=$ & 212 & - & - & - & - & -.41 \\
\hline 11. Green peppers & 17.40 & 2.62 & 2.32 & 8.7 & - & 186 & 195.4 & - & - & 1.76 & .14 \\
\hline 12. Kunde greens & - & - & - & - & .56 & - & - & .79 & - & .67 & -.78 \\
\hline 13. Lettuce & 4.82 & 3.23 & $2.27^{!}$ & 9.3 & - & 239 & 218.1 & .62 & - & .53 & -.21 \\
\hline 14. Mushrooms & - & 7.90 & 5.60 & - & - & 790 & - & - & .54 & 1.95 & 1.00 \\
\hline 15. Onions, yellow & 5.59 & 1.78 & .86 & 4.8 & .67 & $127^{b}$ & 98.6 & .77 & .73 & .35 & $=.66$ \\
\hline 16. Radishes & - & - & - & - & .55 & - & - & - & - & .88 & -.68 \\
\hline 17. Red cabbage & - & 1.27 & .56 & - & - & - & - & - & - & .12 & -1.20 \\
\hline i8. Spinach & 4.71 & - & - & - & - & - & 133.8 & - & - & 1.24 & $-.29^{\prime}$ \\
\hline 19. Tomatoes & 5.79 & 2.55 & 7.85 & 6.7 & 7.21 & 226 & 160.9 & 1.19 & .31 & .92 & -.10 \\
\hline 20. Yellow squash & 2.29 & - & - & 1.5 & - & - & - & - & - & .66 & -1.22 \\
\hline Caefficient $B_{C}$ & 1.96 & .92 & .57 & 2.02 & .34 & 5.68 & 5.32 & .57 & -7.56 & .00 & \\
\hline Antilog & 7.11 & 2.52 & 1.77 & 7.53 & 1.41 & 291.9 & 204.5 & 1.76 & .27 & 1.00 & \\
\hline
\end{tabular}

a Federal Republic of Germany (West Germany).

This entry represents a correction of the corresponding figure in Kravis et.a1. (1975, p. 59). 
equals the geometric mean of $p_{i c}$ over $i=1, \ldots, 20 .^{3}$ However, there are numerous missing prices, indicated by - in Table 1. The approach followed by Kravis et a1. In such a case is a weighted form of least squares, the weight of each country being selected so as to correct for the number of items with missing price data in that country. The $B_{c}$ 's of the 10 countries and their antilogs are shown in the last two lines of Table 1. These antilogs are estimated purchasing power parities of fresh vegetables; when the expenditure on this category is divided by such a PPP, we obtain a volume (volumes and expenditures are all on a per capita basis).

The price-quantity decomposition of the detailed categories is just the beginning. There are tables dealing with these categories in the Appendix of Chapter 6, but these detailed tables are only presented as worksheet materials for the convenience of those who want aggregates other than those considered by the authors. The latter aggregates are 35 "summary categories" (25 in consumption, eight in capital formation, two in government). This is the lowest level of aggregation at which the statistics are considered to be of publishable quality.

Since this journal is not a statistics journal, I will give only a broad outline of the way in which the prices and volumes of the detailed categories have been aggregated to sumary categories and to broader groups. The key is the notion of multilateral price and volume comparisons which are base-invariant. The method used is that proposed by Geary (1958) and amended by Khamis (1967, 1970, 1972). This procedure yields volumes in the form of expenditures expressed in "international prices." Such volumes are additive across expenditure categories, while prices can be obtained by dividing expenditures in national

${ }^{3}$ Similarly, the estimate of $A_{i}$ equals the mean over $c$ of 1 og $P_{i c}$, but the $A_{i}$ 's play no further role. The model, $\log p_{i c}=A_{i}+B_{c}$ ' is characterized by one additive degree of freedom, which has been used in Table 1 by putting $B_{c}=0$ for $c=U$. $S$. 
currency by those in international prices. Columns (2) and (3) of Table 2 provide the results for the per capita volumes of total consumption and gross domestic product. The order in which the countries are listed in that table will. be clarified in Section 3 .

I should emphasize that the picture presented in the three previous paragraphs is oversimplified in a number of respects. Although the CPD method illustrated in Table 1 is the one most commonly used for estimating PPPs of detailed categories, it is not the only one. Sometimes goods can be narrowly defined, but not always. 4 There are "comparison-resistant" services for which different procedures were used (Chapter 5); I should also refer to the automobile and rent regressions on pp. 50-56 and to the discussion of the prices of construction and consumer durables on pp. 47-49.

Another problem has to do with country groups. The 34 participating countries do not just represent themselves; a special weighting scheme is designed to ensure that a closer approximation of the picture for the world as a whole is obtained ("supercountry weighting" on pp. 79-82). Also, given that the book reviewed here deals with as many as 34 countries, the authors discuss extensively whether they should adopt a regional approach by first comparing countries within each region and then comparing regions. They decided against this idea, although there is a regional flavor in their application of the CPD method (see Chapter 4).

The differences between the exchange-rate converted figures and those which Kravis et al. obtain using their preferred method are substantial; not

\footnotetext{
${ }^{4}$ An example of a narrowly defined good is eggs: "fresh chicken eggs, large size (weighing at least 680.4 grams per dozen), white or brown shel1. Not the best quality, but close to it. The white is less thick and high than the best quality; the yolk must be firm, high, and not easily broken" (p. 38). It is also constructive to read what the authors have to say about the work of U. N. and national price experts (same page).
} 
Table 2

SUMMARY MEASURES FOR 34 COUNTRIES $^{\mathrm{a}}$

\begin{tabular}{|c|c|c|c|c|c|c|}
\hline & & Gro & lomestic & oduct & & \\
\hline Country & $\begin{array}{l}\text { Total } \\
\text { consumption }\end{array}$ & $\begin{array}{l}\text { Inter- } \\
\text { national } \\
\text { dollars }\end{array}$ & $\begin{array}{l}\text { Same, } \\
\text { U.S. }=100\end{array}$ & $\begin{array}{c}\text { Exchange- } \\
\text { rate } \\
\text { converted }\end{array}$ & $\begin{array}{l}\text { Budget } \\
\text { share } \\
\text { of food }\end{array}$ & $\begin{array}{l}\text { Information } \\
\text { inaccuracy } \\
1975 \quad 1970\end{array}$ \\
\hline
\end{tabular}

The 0ld Fifteen

$\begin{array}{lr}\text { U. S. } & 4954.5 \\ \text { France } & 3745.6 \\ \text { Germany } & 3743.4 \\ \text { Belgium } & 3715.1 \\ \text { Netherlands } & 3398.1 \\ \text { U. K. } & 3174.0 \\ \text { Japan } & 2912.6 \\ \text { Italy } & 2636.4 \\ \text { Hungary } & 2313.3 \\ \text { Iran } & 1345.3 \\ \text { Colombia } & 1265.4 \\ \text { Korea } & 1019.3 \\ \text { Malaysia } & 939.5 \\ \text { Philippines } & 693.7 \\ \text { India } & 338.0\end{array}$

7176.0
5876.9
5952.7
5574.1
5397.2
4587.9
4906.7
3861.1
3558.9
2704.6
1608.7
1484.1
1540.6
946.3
470.5

100

81.9

83.0

77.7

75.2

63.9

68.4

53.8

49.6

37.7

22.4

20.7

21.5

13.2

6.6

$\begin{array}{lrrrrrr}\text { Luxembourg } & 3934.8 & 5883.4 & 82.0 & 90.2 & .2228 & .0134 \\ \text { Dentmark } & 3887.3 & 5910.9 & 82.4 & 104.5 & .2349 & .0432 \\ \text { Austria } & 3721.4 & 4994.8 & 69.6 & 69.8 & .2323 & .0119 \\ \text { Spain } & 3001.0 & 4010.2 & 55.9 & 41.0 & .3271 & .0141 \\ \text { Ireland } & 2299.3 & 3048.8 & 42.5 & 37.2 & .2946 & .0235 \\ \text { Uruguay } & 2234.3 & 2844.3 & 39.6 & 18.2 & .4192 & .0403 \\ \text { Poland } & 2154.8 & 3597.9 & 50.1 & 36.0 & .3925 & .0232 \\ \text { Mexico } & 1839.4 & 2487.3 & 34.7 & 20.4 & .3836 & .0165 \\ \text { Yugoslavia } & 1712.7 & 2591.4 & 36.1 & 23.2 & .3502 & .0135 \\ \text { Romania } & 1435.4 & 2386.8 & 33.3 & 24.3 & .4149 & .0210 \\ \text { Jamaica } & 1333.0 & 1722.6 & 24.0 & 19.6 & .4029 & .0635 \\ \text { Syria } & 1295.4 & 1794.2 & 25.0 & 10.0 & .5143 & .0469 \\ \text { Brazil } & 1219.0 & 1811.2 & 25.2 & 16.0 & .3680 & .0065 \\ \text { Thailand } & 699.1 & 936.1 & 13.0 & 5.0 & .5108 & .0180 \\ \text { Sri Lanka } & 510.0 & 667.7 & 9.3 & 2.6 & .6814 & .0249 \\ \text { Pakistan } & 441.7 & 590.3 & 8.2 & 2.6 & .5938 & .0534\end{array}$

$\begin{array}{rl}100 & .1586 \\ 89.6 & .2286 \\ 94.7 & .1996 \\ 87.8 & .2255 \\ 84.5 & .2166 \\ 57.6 & .2255 \\ 62.3 & .2613 \\ 47.9 & .3409 \\ 29.6 & .3662 \\ 22.1 & .3402 \\ 7.9 & .3906 \\ 8.1 & .5379 \\ 10.9 & .4023 \\ 5.2 & .6089 \\ 2.0 & .6412\end{array}$

.0194

.0144

$.0074 \quad .0057$

$.0140 \quad .0109$

$.0051 \quad .0061$

$.0092 \quad .0093$

$.0157 \quad .0148$

$.0127 \quad .0245$

$.0094 \quad .0130$

$.0206 \quad .0273$

$.0286 \quad .0442$

$.0170 \quad .0218$

$.0174 \quad .0106$

.0294 .0306

$.0223 \quad .0207$

$.0135 \quad .0075$

The New Sixteen

The African Three

$\begin{array}{lllrrrr}\text { Zambia } & 415.8 & 737.8 & 10.3 & 6.9 & .4065 & .0803 \\ \text { Kenya } & 364.7 & 470.5 & 6.6 & 3.4 & .4395 & .1166 \\ \text { Malawi } & 274.9 & 351.7 & 4.9 & 1.9 & .5806 & .0563\end{array}$

${ }^{\mathrm{a}}$ All figures refer to 1975 except those in column (8).

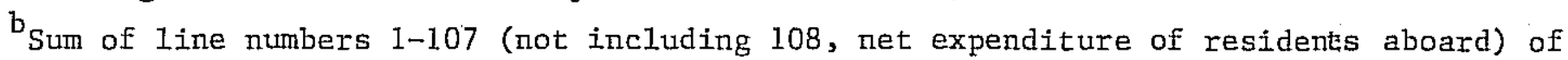
Kravis et al. (1982, Summary Multilateral Table 6-4).

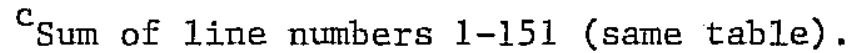

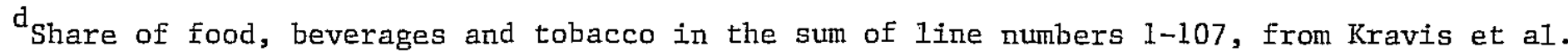
(1982, Summary Multilateral Table 6-1). 
surprisingly, such differences tend to be larger when two countries compared are more different in affluence. This matter is pursued in columns (4) and (5) of Table 2, from Kravis et al. (1982, p. 12), which compare the PPP based estimates of GDP per capita with those based on exchange rates, both as a percentage of the U. S. value. Using exchange rates tends to overstate the poverty of poor nations. A major reason is that services, which are cheaper relative to commodities in poorer countries, are modestly represented in International trade and, hence, in exchange rates. Of course, exchange rates have the additional disadvantage that they have become so variable in recent years.

There is also an extensive discussion of binary (rather than multilateral) comparisons in Chapter 7, including 68 tables in the Appendix of that chapter for 68 country pairs. Extrapolations follow in Chapter 8, and exercises in interspatial demand analysis in Chapter 9.

\section{The Use of the Data}

There are several applications of these data to applied economic analysis. Since consumption tends to be the dominating component of GDP [see columns (2) and (3) of Table 2] and since the 34 countries display a large dispersion in affluence and relative prices, the most obvious application is that to consumer demand analysis, and I will therefore restrict myself in what follows. The authors consider this topic in Chapter 9, which starts with the presentation of $\left(\begin{array}{c}34 \\ 2\end{array}\right)=561$ similarity indexes for prices and quantities, one for prices and one for quantities for each country pair. A similarity index is a correlation coefficient which is located in $(0,1)$ and which attains the upper bound if and only if the prices (or quantities) of the two countries are proporational. Attempts are made to test the relationship between the similarity index of quantities 
and that of prices and other factors, but such tests are seriously hampered by the dependence of the 561 observations. 5

Next is a revealed-preference analysis, the results of which are not very illuminating, and a log-linear demand analysis applied to each of 103 detailed consumption categories and to each of the 25 sumary consumption categories. Some of the results of the latter analysis are definitely illuminating. Bread and rice are two detailed categories. Table 9-4 contains an income elasticity ${ }^{6}$ for bread of 1.26 (standard error .20) and for rice of -.80 (s.e. .36). The former elasticity is far too high, even when we take the standard error into account, and the latter is algebraica1ly too low; these figures simply reflect different consumption habits in different parts of the world. When bread and rice are merged with three other detailed categories into one summary category labeled bread and cereals, the income elasticity becomes .06 with a standard error of .07 (see Table 9-3). This is a much more realistic result; it illustrates that cross-country demand analysis should be based on broad groups of goods. Yet, even the results for summary categories in Table $9-3$ are not really attractive, since the estimates of the own-price elasticities have relatively large standard errors. The most obvious way of improving on this defect is by using a system of demand equations rather than estimating such equations separately. The authors do just this on pp. 366-374 by means of the Iinear expenditure system, which is an unfortunate choice. This system has constant marginal

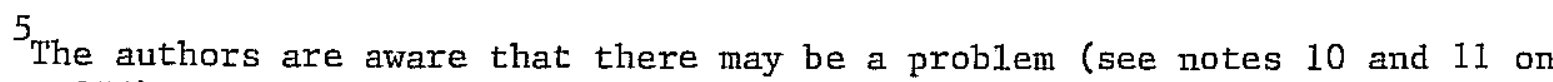
p. 351), but they do not solve it by making caveats about standard errors and F tests. A more straightforward way of exploring similarities and dissimilarities is in terms of Divisia variances; see Theil and Suhm (1981) for such an analysis based on the data of Kravis et a1. (1978a).

Gore precisely, the elasticity with respect to total consumption expenditure, prices remaining constant. I use "income elasticity" here as a convenient
abbreviation. 
shares. ${ }^{7}$ Since the ratio of a marginal share to the corresponding budget share equals the income elasticity, the implication of constant marginal shares is that income elasticities are inversely proportional to the corresponding budget shares. As column (6) of Table 2 shows, the budget share of food (including beverages and tobacco) is less than 20 percent in the U. S. and more than 60 percent in some of the poorest countries. Thus, the income elasticity of food in the U. S. would be on the order of three or four times larger than in the latter countries, which is clearly unrealistic. ${ }^{8}$

Any demand system which is supposed to handle a large degree of income. variation should pay special attention to the position of food in the budget. This is pursued in Figure 1, where the food budget shares of the 34 countries are measured vertically and their total per capita real consumption expenditures [column (2) of Table 2] horizontally, the latter on a logarithmic scale. The points are scattered around a decreasing straight line except the three of the African countries. The declining linear relation between the budget share of food and the $\log$ of total consumption expenditure is known as Working's (1943) model. Theil and Suhm (1981) applied this model to the data for 16 countries published by Kravis et a1. (1978a) and found that the fit was close in all cases except Kenya. Since Kenya's data have other problems also, 9 the model was applied to the remaining 15 countries; these are the 01d Fifteen in the upper part of Table 2, Iisted there according to declining values of total consumption per capita [column (2)]. The $34-15=19$ other countries of the 1982 volume are separated into the New Sixteen and the African Three.

Let $p_{i}$ be the price and $q_{i}$ the quantity of good $i$; then the marginal. share of this good is $\partial\left(p_{i} q_{i}\right) / \partial M$, where $M=\Sigma_{j} P_{j} q_{j}$. The proposition : stated in the next sentence is that the ratio of $\partial\left(p_{i} q_{i}\right) / \partial M$ to $p_{i} q_{i} / M$ equals $\left(\partial q_{i} / \partial M\right) M / q_{i}$. This proposition also holds when the marginal share is not constant. 8 The authors do mention in note 42 on p. 367 that there is a problem, but this does not adequately reveal how serious the problem is. The income and ownprice elasticities in their Table 9-7 are all at sample means; the size of the problen would have been made clearer if these elasticities had also been presented at high and low income levels.

${ }^{9}$ See Isenman (1980). 
Budget share. of food

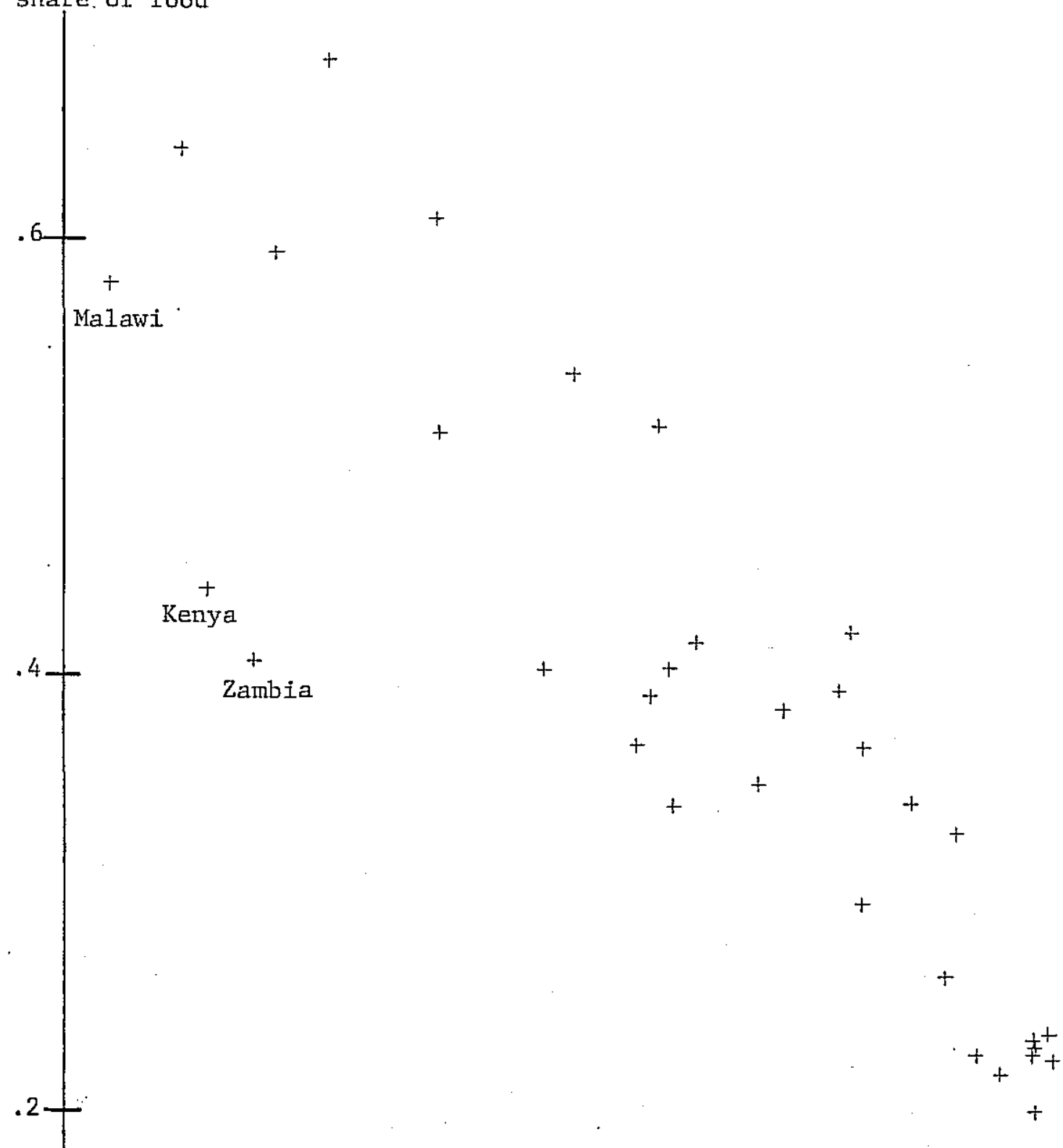

0 250

Total consumption expenditure per capita (in international prices)

Figure 1 
Working's model deals with income effects on consumption, not with price effects; so it was extended to include price effects under the simplifying assumption of preference independence (see Appendix) and applied to eight expenditure categories. ${ }^{10}$ How well does this model fit the new data? Column (7) of Table 2 answers this question by means of.

$$
I_{c}=\sum_{i=1}^{8} w_{i c} \log _{e} \frac{w_{i c}}{\hat{w}_{i c}}
$$

which is the information inaccuracy of the fitted budget shares of country $c, \hat{\mathrm{w}}_{1 c}, \ldots, \hat{\mathrm{w}}_{8 \mathrm{c}}$, given that country's observed budget shares $\mathrm{w}_{1 c}, \ldots, \mathrm{w}_{8 \mathrm{c}}$. The larger $I_{c}$, the worse the fit. The arithmetic average inaccuracy for the 0ld Fifteen is .0161. Column ( 8 ) gives the inaccuracies of the fitted budget shares in 1970, based on the data of Kravis et al (1978a) from which the model was derived. The average of the latter inaccuracies is .0174; hence the above-mentioned average of .0161 is encouraging. For the New Sixteen the average inaccuracy in column ( 7 ) is .0271; this is higher, which is not surprising given that the data of none of these countries were used in the fitting of the coefficients of the model. For the African Three the average inaccuracy in column (7) is .0844, which-is much higher. This indicates either

\footnotetext{
10 The eight categories are food, beverages and tobacco; clothing and footwear; gross rent and fuel; house furnishings and operations; medical care; transport and communication; recreation and education; other consumption expenditures. Preference independence means that the consumer's tastes can be described by means of a utility function which j.s additive in these eight categories. The linear expenditure system satisfies preference independence, since this system can be viewed as being associated with a utility function which is a weighted mean (with the marginal shares as weights) of $\log \left(q_{i}-\gamma_{i}\right)$. The constancy of the marginal shares is the major weakness of this system in the present context, but the inequality constraint $q_{i}>\gamma_{i}$ also causes problems, particularly with respect to the standard errors of the $\gamma_{i}$ estimates.
} 
different tastes or data problems or both. ${ }^{11}$ It is tempting to refit the model for appropriate subsets of the 34 countries, but such an analysis is beyond the scope of this article.

Working's model implies that each marginal share exceeds the corresponding budget share by a constant. For food this constant is negative, yielding an income elasticity of food which declines as income rises. This is far more realistic than the behavior of this elasticity which is implied by the linear expenditure system. When rereading their Chapter 9, I have difficulty believing that the authors always believed in what they wrote. "The simplest extension explicitly assumes that each consumer in a country consumes the per capita quantity of each good ..." (p. 354); surely, after all those years struggling with those data, the authors must be acutely aware that variations within a country are not at all negligible compared with per capita variations across countries. Yet, as far as the construction of the basic data is concerned, their work is better than what anyone before has performed. In Trumanesque terms, they did their damndest. Of course, this does not mean that their figures are perfect; it is up ta the user of these figures to apply.his own judgments, which is considerably simplified by the authors' frank admission of the difficulties which they fäced and the implied limitations.

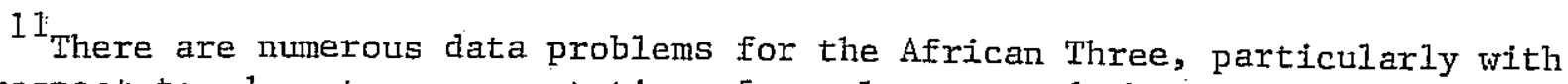
respect to adequate representation of rural areas and the estimates for rent and medical care (see pp. 42, 44-45, 54, 57). Indeed, it may well be the case that these countries are not yet ready for the kind of statistical exercise to which Kravis et al. subjected them. Another country whose data deserve our suspicion is Jamaica. It has the highest information inaccuracy out of alI countries except the African Three. A closer look at Jamaica's data indicates that the largest discrepancy is that between the predicted and observed budget shares of other consumption expenditure. It seems likely that the hotel and restaurant component of this category refers mainly to expenditures by foreign tourists rather than by domestic consumers. 
APPENDIX

Let $p_{i}$ be the price, $q_{i}$ the quantity and $w_{i}=p_{i} q_{i} / M$ the budget share of good $i$, where $M=\Sigma_{j} \mathrm{P}_{j} \mathrm{q}_{j}$ is total expenditure (or "income"). Working's model states

$$
w_{i}=\alpha_{i}+\beta_{i} \log M
$$

Multiplication of (1) by $M$ and subsequent differentiation with respect to $M$ yields $\partial\left(p_{i} q_{i}\right) / \partial M=\alpha_{i}+\beta_{i}+\beta_{i} \log M$ and hence, in view of (1),

$$
\frac{\partial\left(p_{i} q_{i}\right)}{\partial M}=w_{i}+\beta_{i}
$$

Theil and Suhm (1981) applied this model to the first 15 countries of Table $2(c=1, \ldots, 15)$ at the geometric means of the prices of the eight goods across countries, 12

$$
\log \overline{\mathrm{p}}_{i}=\frac{1}{15} \sum_{\mathrm{c}=1}^{15} \log \mathrm{p}_{i c}
$$

where $P_{i c}$ is the price of good $i$ in country c. This amounts to $\overline{\mathrm{w}}_{i c}=\alpha_{i}+\beta_{i} \log Q_{c}+\varepsilon_{i c}$, where $E_{i c}$ is a random disturbance, $Q_{c}$ is per capita real income of country $c$ [column (2) of Table 2, normalized so that $Q_{c}=1$ for $c=U$. S.], and $\bar{w}_{i c}$ is the budget share of good $i$ at the prices $\overline{\mathrm{P}}_{1}, \ldots, \overline{\mathrm{p}}_{8}$ and the observed $\mathrm{Q}_{c}$. Therefore,

$$
w_{i c}=\alpha_{i}+\beta_{i} \log Q_{c}+\left(w_{i c}-\bar{w}_{i c}\right)+\varepsilon_{i c}
$$

12

Since Working (1943) applied his model to household data collected during the same period and in the same country, he did not have to worry too much about differences in relative prices, but the situation is obviously different in a cross-country context. 
where $w_{i c}$ is the observed budget share of good $i$ in country $c$ [see column (6) of Table 2 for $i=$ food].

The difference $w_{i c}-\bar{w}_{i c}$ in (4) results from the difference between the price vectors $\left[\mathrm{p}_{i c}\right]$ and $\left[\overline{\mathrm{p}}_{i}\right]$. Using the differential approach to consumption theory, ${ }^{13}$ we find that $w_{i c}-\bar{w}_{i c}$ can be written as the sum of two terms,

$$
w_{i c}-\bar{w}_{i c}=w_{i c}\left(\log \frac{p_{i c}}{\bar{p}_{i}}-\sum_{j=1}^{8} w_{j c} \log \frac{p_{j c}}{\bar{p}_{j}}\right)+\sum_{j=1}^{8} \pi_{i j} \log \frac{p_{j c}}{\bar{p}_{j}}
$$

where $\pi_{i j}$ is a slutsky coefficient. The first term on the right in (5) represents the change in the budget share which results from the change from $\left[\bar{p}_{i}\right]$ to $\left[p_{i c}\right]$ when the consumer buys the same quantities in spite of the price change; the second term describes the substitution effect of the price change.

We have $\pi_{i j}=\phi\left(\theta_{i j} \delta_{i j}-\theta_{i} \theta_{j}\right)$ under preference independence, where $\theta_{i}$ is the marginal share of good $i, \delta_{i j}$ is the Kronecker delta and $\phi$ is the reciprocal of the income elasticity of the marginal utility of income. We use (2) to write the marginal share of good $i$ in country $c$ as $w_{i c}+\beta_{i}$. The result is that, under preference independence, the substitution term in (5) can be written as

$$
\phi\left(w_{i c}+\beta_{i}\right)\left[\log \frac{P_{i c}}{\bar{P}_{i}}-\sum_{j=1}^{8}\left(w_{j c}+\beta_{j}\right) \log \frac{P_{j c}}{\overline{\bar{p}}_{j}}\right]
$$

The final result is obtained by combining (5) and (6) with (4), yielding the maximum likelihood estimates shown in Theil and Suhm (1981, p. 44). Predicted budget shares $\hat{w}_{i c}$ are then obtained from (4) by deleting $\varepsilon_{i c}$. See Theil and Suhm (1981, Section 4.1) for the implied income and price elasticities at various levels of real income.

13 See Theil (1980) for details on this approach. 


\section{REFERENCES}

Clark, C. (1940). The Conditions of Economic Program. London: Macmillan.

Geary, R. C. (1958). "A Note on Comparisons of Exchange Rates and Purchasing Power Between Countries." Journal of the Royal Statistical Society (A), 121, pp. 97-99:

Gilbert, M., and Kravis, I. B. (1954). An International Comparison of Nationa1 Products and the Purchasing Power of Currencies. Paris: Organisation for European Economic Co-operation.

Isenman, P. (1980). "Inter-country Comparisons of 'Real' (PPP) Incomes: Revised Estimates and Unresolved Questions." World Development, 8, pp. 61-72.

Khamis, S. H. (1967). "Some Problems Relating to International Comparability and Fluctuations of Production Volume Indicators." Bulletin of the International Statistical Institute, 42, pp.213-230.

Khamis, S. H. (1970). "Properties and Conditions for the Existence of a New Type of Index Number." Sankhyāa, B, 32, pp. 81-98.

Khamis, S. H. (1972). "A New System of Index Numbers for National and International Purposes." Journal of the Royal Statistical Society (A), 135, pp. $96-121$.

Kravis, I. B., Heston, A. W., and summers, R. (1978a). International Comparisons of Real Product and Purchasing Power. Baltimore, Md.: Johns Hopkins University Press.

Kravis, I. B., Heston, A. W., and Summers, R. (1978b). "Real GDP Per Capita for More Than One Hundred Countries." Economic Journa1, 88, PP. $215-242$.

Kravis, I. B., Heston, A., and Summers, R. (1982). World Product and Income. Baltimore, Md.: Johns Hopkins University Press.

Kravis, I. B., Kenessey, Z., Heston, A. W., and Sumers, R. (1975). A 


$$
-16-
$$

System of Internationa1 Comparisons of Gross Product and Purchasing Power. Laltimore, iid.: Johns lloplins University Press.

Kuznets, S. (1957-67). "Quantitive Aspects of Economic Growth of Nations, I - X." Economic Development and Cultural Change.

Leontief, W. W. (1951). The Structure of American Economy, 1919-1939, Second edition, Oxford University Press.

Leontief, W. W. (1971). "Thesretical Assumptions and Nonobserved Facts." American Economic Review. 61, pp. 1-7.

Summers, R., Kravis, I. B., and Heston, A. W. (1980). "International Comparisons of Real Product and Its Composition: 1950-77. " Review of Income and Wealth, 26, pp. 19-66.

Thei1, H. (1980). The System-Wide Approach to Microeconomics. Chicago: University of Chicago Press.

Theil, H. and Suhm, F. E. (1981). International Consumption Comparisons. With an Appendix by J. F. Meisner. Amsterdam: North-Holland Publishing Company. Working, H. (1943). "Statistical Laws of Family Expenditure." Journal of the American Statistical Association, 38, pp. 43-56. 